\title{
Uncovering Powerful East Asian Women Politicians in News Media
}

\author{
Tsz Lam Ngai \\ University of Cambridge, United Kingdom \\ natalietszlam@gmail.com
}

\begin{abstract}
This article investigated the media representation of women politicians in mediated political communication in the context of Hong Kong, China. It attempted to supplement the previous feminism scholarship on media representation of women activists, which largely situated in Western contexts, with the example from East Asia. Contrary to the studies worldwide which argued that women politicians were confined to the trivialized topics in news media, this article demonstrated that the East Asian women politicians in Hong Kong, a special administrative region of China which was colonized by Britain, were visible in a larger variety of topics than their male counterparts in newspapers and they were more often directly quoted than the male politicians. Also, the number of editorials women politicians wrote to the mainstream press was significantly higher than the men did. Despite these, those articles the women are in occupied latter sections. A subtler analysis also discovered that the promising trends applied only to a few celebrity women politicians. These findings were based on a content analysis of 946 news articles in four Hong Kong newspapers. The conclusion discussed how the findings could inform readers about the stereotype towards East Asia as a highly patriarchal culture influenced by Confucianism in contemporary mediated political communication.
\end{abstract}

KEY WORDS: media representation, politics, gender, women in power, celebrity, East Asia. 


\section{Introduction}

Mass media is crucial for the circulation of political discourse among a wider audience especially in Hong Kong, which has a high level of media consumption. There are 55 registered newspapers in Hong Kong and the city has one of the highest newspaper readerships in Asia (HKSAR Government 2015). Yet, research on politics, media and gender in the context of Hong Kong is very limited. The Global Media Monitoring Project (GMMP), the largest international study on gender and media since 1995, has not included Hong Kong, not even China, until 2015. Research on women-in-power in Hong Kong is still by large limited to descriptive statistics like the proportion of women leaders (e.g Cheung and Lee 2012, 191-223). Only one qualitative study by Lee (2004, 207-25) argued about the 'perfect women' representation of women politicians is found. There is a lack of robust study on women representation of women-inpower in the context of Hong Kong while this area of study has already developed a sophisticated scholarship in the West, which found that powerful women appeared less significant in news media (Luenenborg et al. 2011, 57-75; Ross and Cynthia 2013, 1148-165; Sreberny and van Zoonen 2000, 5-20). This pattern of trivializing powerful women by media was found also in democratizing countries and regions (Kasoma 2014, 70-83). It is hence of urgent need to conduct an empirical research on media representation of women politicians in Hong Kong.

\section{Method}

Content analysis is employed to examine the media visibility of women and men politicians across four newspapers which can represent an array of political approaches and mainstream journalistic style of newspapers in Hong Kong (Lee and Chan 2010, 67). These are Apple Daily, Ming Pao, Oriental Daily and Wen Wei Po. Articles published and dated 29/9/2014 - 16/12/2014 during the occupation period of the Umbrella Movement, with the names of 40 directly-elected legislators of the Legislative Council of Hong Kong ( $\mathrm{LegCo}$ ) mentioned, are selected for content analysis from the database Wisenews. Only articles with 250 words or above devoted to the legislators are included in the final sample, which consists of 274 articles for the 11 women legislators and 672 articles for the 29 men legislators. In this article, four variables are focused including 'Topic' and 'Placement' of the articles, as well as 'Role' of the politicians and Attribution of Speech' when citing politicians' words in the particular articles. The significance level for the following statistical analyses is 0.05 . 


\section{Results}

Women have been mentioned in more diverse topics than men as represented by the more colorful pie chart in women (Figure 1). Still, men are more dominant compared to women in terms of placement as illustrated in Figure 2. Only men $(n=20)$ but no woman have been mentioned on 'Front Page'.

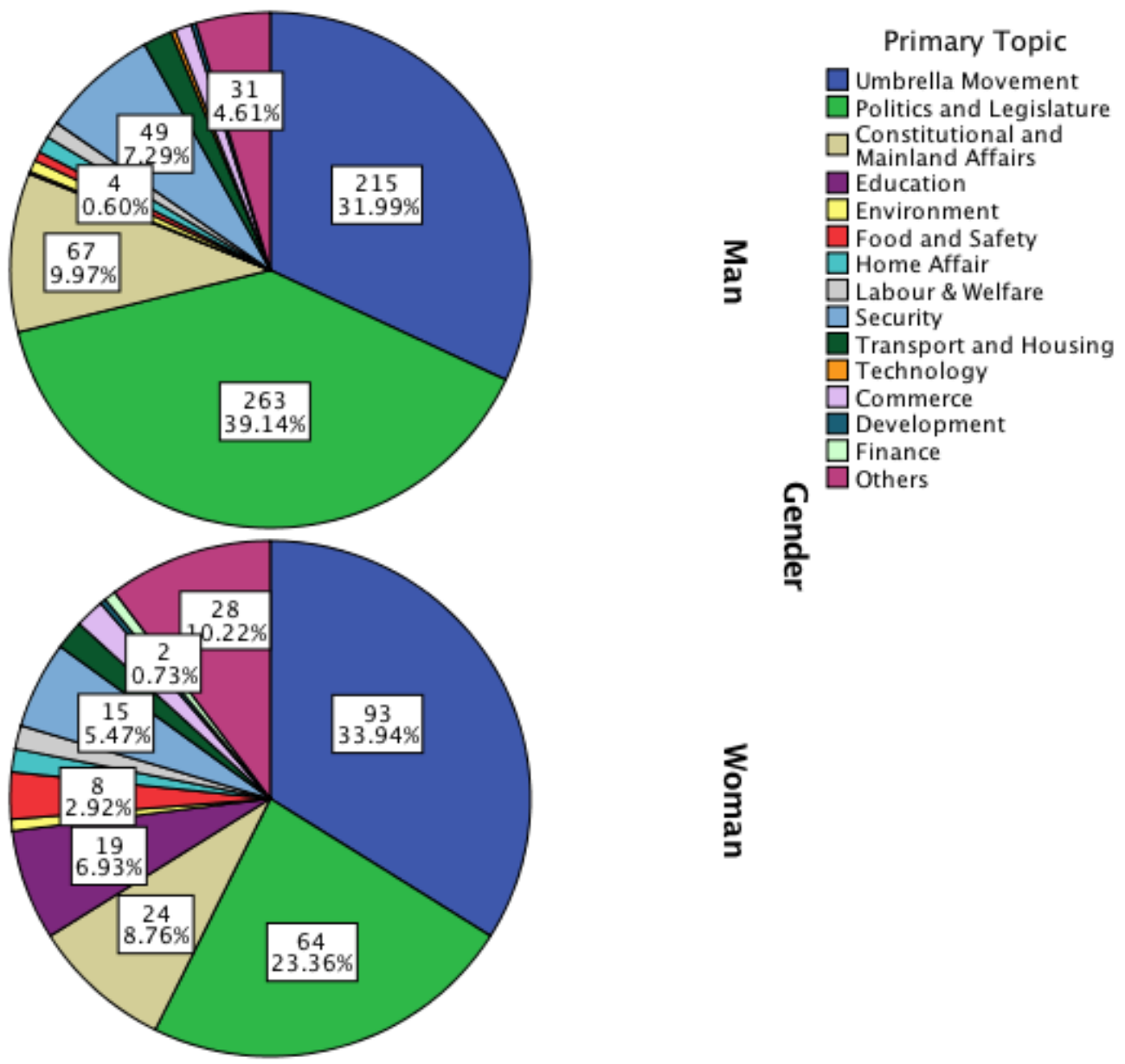

Figure 1. Distributions of topics within each gender 


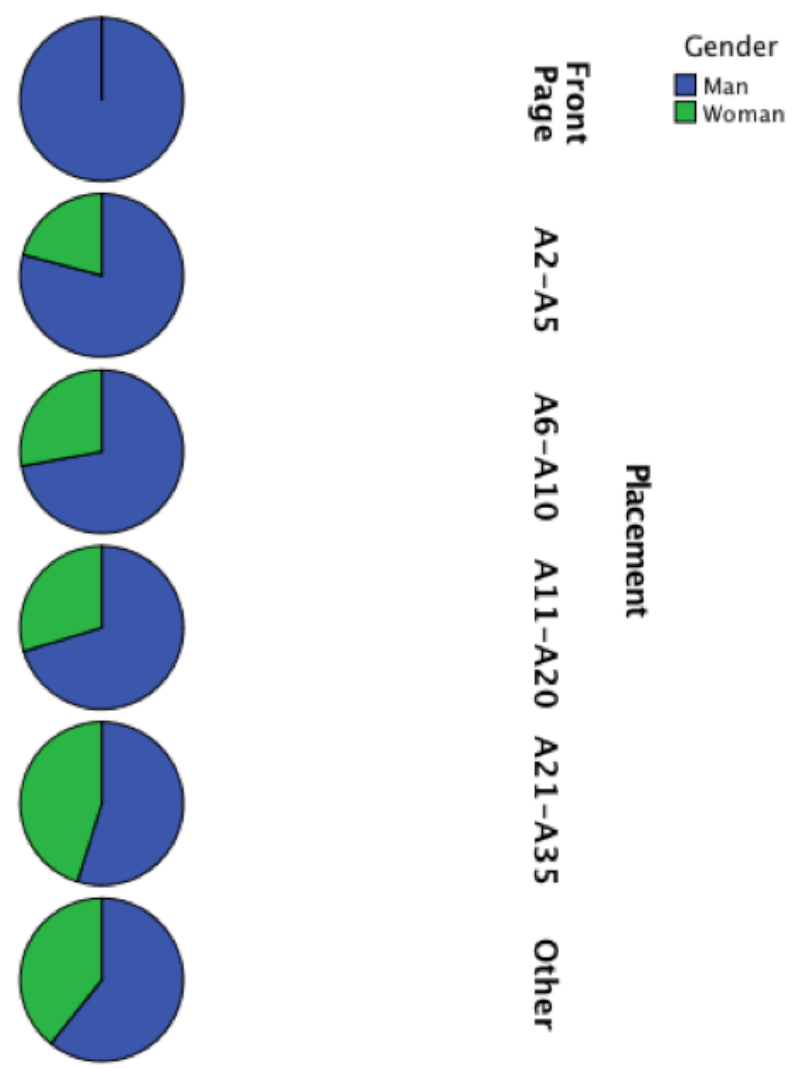

Figure 2. Article distributions in different sections of newspapers

A regression analysis confirms that the words of women are more likely to be quoted than that of men when they are mentioned in media (Table 1). When 'N/A' (no word is quoted from the legislator) is set as the reference category, all $p$-values are lower than 0.05 and all $B$ values (man over woman) are negative. It is statistically significant $(p<0.05)$ that men are less likely than women to be quoted by 'Direct Quotation,'Paraphrase' and 'Mixed' when they are compared with 'N/A' (no words are quoted) respectively. 
Table 1. Multi-nominal logistic regression results of 'Gender' against 'Attribution of Speech'

\begin{tabular}{lll} 
Attribution of Speech & $\begin{array}{l}\text { B Value } \\
\text { (man over woman) }\end{array}$ & Sig. (p-value) \\
\hline Direct Quotation & -1.420 & $0.000^{* * *}$ \\
Paraphrase & -0.410 & $0.046^{*}$ \\
Mixed & -1.043 & $0.000^{* *}$ \\
\hline
\end{tabular}

(The reference category is $\mathrm{N} / \mathrm{A} ;{ }^{*} \mathrm{p}<0.05,{ }^{* *} \mathrm{p}<0.01,{ }^{* * *} \mathrm{p}<0.001$ )

Women politicians also write more to the press than their male counterparts, with $60 \%$ of the articles written by politicians in the sample are women authors. A regression analysis also supports this as it is statistically significant $(p<0.05)$ that men are less likely than women to be represented as 'Writer' over 'Protagonist' ( $p$-value is 0.000 and $B$ value is -1.361 ), while the application of this trend to other roles over 'Protagonist' is statistically inconclusive (Table 2). In sum, it confirms that 'Writer' is a distinctively feminized role. ('Protagonist' is set as the reference category in the test since the observed gender proportion of 'Protagonist' (men $27.8 \%$ * women $72.2 \%$ ) is closest to the expected gender proportion of media visibility (men $27.5 \%$; women $72.5 \%$ ) among roles.)

\section{Table 2. Multi-nominal logistic regression results of 'Gender'against 'Role'}

\begin{tabular}{lll} 
Role & $\begin{array}{l}\text { B Value } \\
\text { (man over woman) }\end{array}$ & Sig. (p-value) \\
\hline Event Participant & 0.322 & 0.191 \\
Commentator & -0.079 & 0.666 \\
Reference & 0.414 & 0.086 \\
Writer & -1.361 & $0.000^{* * *}$ \\
\hline
\end{tabular}

(The reference category is Protagonist; ${ }^{*} \mathrm{p}<0.05,{ }^{* *} \mathrm{p}<0.01,{ }^{* * *} \mathrm{p}<0.001$ )

Notwithstanding the overall promising findings, the media visibility is concentrated on individual legislators regardless of gender as demonstrated by the large standard 
deviations and ranges (Table 3). For example, the highest count of articles for women is devoted to Regina Ip $(n=102)$ and the lowest is Starry Lee $(n=8)$.

Table 3. Distributions of media visibility among legislators with different genders

\begin{tabular}{lll} 
& Women & Men \\
\hline Standard Deviation & 26.8 & 24.9 \\
Range & 94 & 112 \\
\hline
\end{tabular}

\section{Conclusions}

Contrary to the studies which showed that women politicians were confined to the trivialised topics in media, the findings here reveal that women politicians in Hong Kong are mentioned in a larger variety of topics in newspapers than men, the words of women are more likely to be quoted whenever the lawmaker is mentioned, and women politicians write more to the press. Despite that women do not show up in prior news agenda when compared to men, women politicians are not only represented as speaking subjects in news but they can actively influence public opinion by writing columns.

One reason for the general promising trend is the wider scope of this research. Unlike the studies that usually focus on only important 'hard' news like coverage of an election or a campaign (Devitt 2002, 445-63; Ross et al. 2012, 3-20), this research recruits sample on the basis of politicians such that it considers the articles that mentioned them including the peripheral issues and genres across different news events. For example, seldom did previous studies look into women politicians as writers and that is a distinctively feminized role as found here. In other respect, the antithesis of politics and femininity manifested in Western media (van Zoonen $2006,287-301)$ could not be taken for granted, as Lee (2004,207-25) also found that women politicians in Hong Kong were represented in media as the 'perfect women' who could succeed in both politics and family and consisting of both rationality and compassion. The perception towards East Asia as a highly patriarchal culture influenced by Confucianism that have relegated women to an extremely subordinate position is hence dubious (Chiu and Wong 2005, 73-94; Lee and Clark 2000, 4). Nevertheless, it should be noted that the overall promising trend towards the media representation of women can only be attributed to only a few politicians in Hong 
Kong. It agrees with other studies which suggested media tends to concentrate on a few 'superstars' and a large group of qualified women are neglected in other contemporary contexts (van Zoonen 2005, 69-86). Noteworthy also is the phenomenon of personification applies to all gender as found here.

\section{References}

Cheung, F. and Lee, E. 2012. "Women in Power and Decision Making." In Women and Girls in Hong Kong edited by S. Choi and F. Cheung, 191-223. Hong Kong: The Women's Foundation.

Chiu, Sammy, and Victor Wong. 2005."Hong Kong: from familistic to Confucian welfare." East Asian Welfare Regimes in Transition: From Confucianism to Globalization, 73-93. Bristol: Policy Press.

Devitt, James. 2002. "Framing gender on the campaign trail: female gubernatorial candidates and the press." Journalism \& Mass Communication Quarterly, 79(2): 445-63.

Hong Kong Special Administrative Region (HKSAR) Government. 2015. "Hong Kong: The Facts." Accessed Sep 13, 2017. http://www.gov.hk/en/about/abouthk/factsheets/docs/ coming_hk.pdf.

Kasoma, Twange. 2014."Zambia women MPs: An examination of coverage by the Post and Zambia Daily Mail." Women in Politics and Media: Perspectives from Nations in Transition, edited by Raicheva-Stover \& Elza Ibroscheva, 70-83. London: Bloomsbury.

Lee, Francis L.F. 2004. "Constructing Perfect Women: The Portrayal of Female Officials in Hong Kong Newspapers." Media, Culture E Society, 26.2: 207-25.

Lee, Francis L.F, and Chan, Joseph Man. 2010. Media, Social Mobilisation and Mass Protests in Post-colonial Hong Kong, 67. Hoboken: Taylor \& Francis.

Lee, Rose Jungja, and Clark, Cal. 2000. Democracy and the Status of Women in East Asia. Boulder (Colo.): L. Rienner.

Luenenborg, Margreth, Roeser, Jutta, Maier, Tanja, Mueller, Kathrin Friederike. 2011.“Gender analysis of mediated politics in Germany." Gendered Transformations. Theory and Practices on Gender and Media, edited by Tonny Krijnen, Claudia Alvares, and Sofie Van Bauwel, 57-75. Bristol/Chicago: Intellect.

Ross, Karen, and Cynthia, Carter. 2011. "Women and News: A long and Winding Road." Media, Culture E Society, 33.8: 1148-165.

Ross, Karen, Evans, Elizabeth, Harrison, Lisa, Shears, Mary, and Wadia, Khursheed. 2012. "The gender of news and news of gender: a study of sex, politics, and press coverage of the 2010 British general election." The International Journal of Press/Politics, 18(1):3-20. 
Sreberny, Annabelle, and van Zoonen, Liesbet. 2000. Gender, politics and communication. Cresskill, N.J: Hampton Press.

Van Zoonen, Liesbet. 2005. Entertaining the citizen: When politics and popular culture converge, 69-86. Rowman \& Littlefield.

Van Zoonen, Liesbet. 2006. "The personal, the political and the popular: A woman's guide to celebrity politics." European journal of cultural studies 9.3: 278-301. 